\title{
Innovation of Education Management of Application-Oriented Undergraduate Colleges in Big Data Era
}

\author{
Chao Wang \\ Heilongjiang University of Finance and Economics, Harbin 150025, China \\ 714114858@qq.com
}

\begin{abstract}
With the popularization of the Internet, people generate huge amounts of data every day in their daily work and life, which indicates that human civilization has entered the big data era. Under such background, advanced technology should be actively introduced into the management work of application-oriented undergraduate colleges to achieve the innovation of college management mode. Only in this way can a good foundation be laid for promoting the development of talent training in colleges and universities in China. In view of this, first of all, the university management innovation mode under the background of big data era is briefly analyzed, and the support system for management innovation in application-oriented undergraduate colleges under the background of big data era is discussed in detail for reference.
\end{abstract}

Keywords: Big data era, Application-oriented undergraduate, Education management, Innovation

\section{Analysis of the dilemma of application-oriented undergraduate colleges}

\subsection{Characteristics of application-oriented undergraduate colleges}

Application-oriented undergraduate colleges are an important base for personnel training in our country and the product of the development of the education system that is suitable for the new era [1][2][3][4]. How to improve the quality of education management in the context of the big data era requires college administrators to exert their subjective initiative in their work, actively introduce advanced big data technology, strengthen the personalized, refined and scientific characteristics of college management, and carry out innovative research on the education management mode, so as to help college administrators to obtain structured and systematic data in the actual management work and lay a good foundation for promoting the development of college management [5].

For undergraduate colleges that define their type as application-oriented, their service is defined as serving the local regional economic and social development. 'Applicationoriented' means focusing on the training of students' practical ability and ability to solve practical problems according to the market demand for talents and the regional social development. The characteristics of teaching management in application-oriented universities are different from those in research-oriented or teaching-oriented

Article history:

Received (May 24, 2018), Review Result (July 24, 2018), Accepted (October 23, 2018) 
universities, so its education management is unique. In practice, its characteristics are as follows: discipline construction must be close to the market and serve the needs of local economic and social development; Curriculum construction should aim at the quality structure of application-oriented talents in the production frontier and build an application-oriented curriculum system [6]. The teaching process should be combined with the production process to highlight the training of abilities.

Therefore, in the training plan, we have fully implemented the credit system with flexible schooling system and primary and secondary education system as its main contents, and with 'specification plus specialty' and 'quality plus ability' as its main features. In terms of training mode, we emphasize that students should 'have one specialty and multiple certificates' and actively encourage students to take various qualification and level examinations (such as lawyer qualification certificate, accountant qualification certificate, customs declarant qualification certificate, teacher qualification certificate, etc.) while studying their major well. In terms of training methods, we pay attention to the combination of theory and practice, study and research, encourage students to actively participate in teachers' scientific research activities, and enhance students' staying power in serving the society [7].

\subsection{Dilemma of application-oriented undergraduate colleges}

Application-oriented undergraduate education has already received the attention of the Ministry of Education and has already begun to take shape in the reform of undergraduate education. Even though the application-oriented undergraduate education in our country has achieved certain results, the application-oriented undergraduate education is still in the process of continuous improvement, which can neither be finished overnight nor in a hurry. Especially from the perspective of the current situation of our education, the application-oriented undergraduate education will still be in its infancy for a long time to come.

\subsubsection{Difficulty in resource allocation}

In general, the lack of assistance for application-oriented undergraduate students in the early stage of their development is due to the difficulty in the allocation of resources and the lack of policy support. The difficulty in the allocation of resources is mainly reflected in the following two aspects: First, the allocation of funds for university education is not in place. At present, the source of funding for education in our country has always been provided unilaterally by the government. However, application-oriented undergraduate education needs not only the necessary subsidies from the local government, but also constant exchanges and cooperation with local enterprises and industries to create favorable conditions for college students to practice. However, the shortage of funds in this area is very serious and cannot meet the requirements for the allocation of funds for application-oriented undergraduate education. In addition, the shortage of funds for application-oriented undergraduate education is exacerbated by the competition of funds from some established undergraduate colleges. Second, students are not qualified. China's college entrance examination admission system has a long history and it is difficult to break the traditional situation in a short period of time. Therefore, the new type of undergraduate education has no advantage in the admission of students. From the point of view of policy support in China, although the newly-built application-oriented undergraduate course in China falls into the category of vocational education at the undergraduate level in essence, the development of application-oriented undergraduate 
education is still in the development stage and is not perfect in all aspects. Although the Chinese government has formulated a series of supporting policies in this period, its development is restricted by the general higher education system. Therefore, the application-oriented undergraduate cannot get any policy support from the education system in its development process.

\subsubsection{School-enterprise cooperation needs to be strengthened}

Characteristic education is the key to the success of application-oriented undergraduate colleges, and the characteristics of a college often determine the level of a college. It is no exaggeration to say that characteristic education is the only way out for newly-built application-oriented undergraduate colleges in China. In the aspect of enrollment, financial support, teachers or any other aspects, application-oriented undergraduate colleges are unable to compete with traditional undergraduate colleges. Nevertheless, because application-oriented undergraduate colleges are newly established colleges and have no heavy burden in running schools, they can find specialties that meet their own characteristics from the very beginning of their establishment, so as to improve their reputation and achieve long-term development. For the application-oriented universities, if the characteristic specialty is their fundamental, the school-enterprise cooperation should be the development path of the application-oriented colleges. School-enterprise cooperation is a good way to achieve a win-win situation between schools and enterprises. It can not only provide internship for students, but also reduce the cost of specialized personnel recruitment for enterprises. However, as far as the current situation is concerned, the situation of school-enterprise cooperation is not optimistic. The main reason is that this way of running a college is still in an ideal state and there is no mechanism for reference, resulting in many colleges and universities not having the opportunity to connect with enterprises, making it difficult for schools and enterprises to run jointly. Even though some colleges and universities have reached some agreements with enterprises, most enterprises focus on the maximization of interests and do not assume the obligation of being educators, and do not educate students in values and professional outlook.

\subsubsection{Teachers need to be further improved}

Whether in the traditional undergraduate education or in the application-oriented undergraduate education, teachers play a very important role. The newly-built application-oriented universities not only have the same shortage of teachers as the traditional universities, but also have some shortcomings. First, the team structure not reasonable. Although the orientation is application-oriented, the actual teachers in these application-oriented undergraduate colleges are mostly research-oriented teachers. Experienced application-oriented teachers are not enough. Second, the 'specialization' of teachers is not strong. The specialization mentioned herein is a specialization that pays equal attention to both practice and theory, while there are very few specialized teachers in the current application-oriented colleges. From a long-term point of view, students who are separated from practice and study blindly are not talents needed by the market, while students who are separated from research and only do practice are not talents needed by the market, either. Only the combination of theory and practice is the talents truly needed by the market. 


\section{Analysis on the influence of education management of application- oriented undergraduate colleges in big data era}

Big data is the most fashionable term nowadays. Mckinsey \& Company put forward the concept of 'big data' for the first time in its report Big Data: The Next Frontier of Innovation, Competition and Productivity. Generally speaking, big data refers to all the information collected and sorted out over a long period of time using specialized software tools. This information is multifarious, comprehensive and diversified, and requires new processing modes or tools to find useful information from it. Then came data warehouse, data analysis, data mining, data security and other technologies around big data, and later became the focus for professionals to study. Big data technology is not about how much information you have, but how to handle such data with special meanings.

The data of management model of colleges and universities involves all aspects of the school, including the establishment of management institutions and the implementation of their functions, management information materials in all aspects, the construction and implementation of management rules and regulations, the basic composition and quality of management personnel, etc. Such data is required to have features of completeness, integrity and accuracy, and requires concerted efforts from both the management department and the technical department to establish a relatively high-quality data management system suitable for decision-making. This is a good opportunity to solve the dilemma for the application-oriented colleges in the initial stage.

\section{Innovation of education management mode of application-oriented undergraduate colleges in big data era}

In the field of education management, big data has also attracted the attention of the global education industry. Horizon Report: 2013 Higher Education Edition jointly released by the new media consortium and the Edu-Cause Learning Initiative points out that there are six technologies that will have an impact on global education in the next five years. The technologies related to big data application are Learning Analysis and MOOK. Mike Timms pointed out the way big data changes the school management system and the development trend of big data in the future teaching management for colleges. Chang Ming (2016) believes that the emergence of big data technology can provide an innovative platform for the management mode of college students, teaching and personnel. Zhang Junchao (2016) believes that under the background of big data era, university management should make use of and analyze the relationship between data to form a scientific management mode based on data. Li Xiaodong (2015) found through analysis that big data makes talent information more scientific and quantifiable, and universities can successfully introduce, screen, evaluate and develop talents by using the huge amount of basic data provided by big data.

The challenges brought about by the big data era are obvious. More and more information generated actively by teachers and students and automatically formed by equipment can be collected. Application-oriented colleges should set up a complete data collection system and analyze the collected data to improve the colleges and enhance their own competitiveness. 


\subsection{Construction of big data database of concepts of running colleges}

The concepts of running colleges is the key to the construction of local applicationoriented undergraduate colleges and plays a vital role in the construction and promotion of their soft environment. Local application-oriented undergraduate colleges are generally developed in accordance with local economic needs and on the basis of regional advantages and have their own specific service orientation. In the big data era, local application-oriented undergraduate colleges should collect relevant information and materials such as historical development, school resources, school ethos, customs, professional settings, quality of students, employment of graduates and outstanding alumni to determine their own concept of running the colleges and provide good guarantee for the future development of the colleges.

\subsection{Construction of big data database of management mode}

The management mode of colleges is an important part of the soft environment of colleges and the key to the construction of the soft environment. This kind of data involves all aspects of the school, including the establishment of management institutions and the implementation of their functions, management information materials in all aspects, the construction and implementation of management rules and regulations, the basic composition and quality of management personnel, etc. Such data is required to have features of completeness, integrity and accuracy, and requires concerted efforts from both the management department and the technical department to establish a relatively high-quality data management system suitable for decision-making.

\subsection{Construction of big data database of campus culture}

The connotation of campus culture is very rich and directly affects the soft environment of colleges. The construction of the database of such big data mainly includes the construction of material culture, spiritual culture, institutional culture, behavioral culture, media culture and so on, collection of colleges' educational philosophy and ideas, related activities, ethics, humanistic atmosphere, teaching style and study style, working style, and information released by various campus media, which can form a campus cultural environment suitable for the development of the colleges and play an irreplaceable and positive role in stimulating creativity and enhancing cohesion of teachers and students. [Figure. 3] Schematic Diagram of Big Data Database of Campus Culture

\subsection{Construction of big data database of scientific research environment}

The informatization of scientific research can provide researchers with personalized advice for grant application and convenient, quick and accurate access to research materials, which has become an important factor in promoting the development of colleges and serving the society. The construction of big data database of scientific research in application-oriented undergraduate colleges can provide targeted help for teachers to carry out scientific research activities. Through big data analysis, teachers can be provided with subject development frontiers, current research hotspots and the latest methods of academic research, so as to facilitate teachers in application-oriented colleges to make breakthroughs in scientific research. 


\subsection{Construction of big data database of teaching environment}

Teaching environment is the fundamental link in the soft environment of applicationoriented undergraduate colleges, and plays a very important role in the construction of soft environment in colleges. The establishment of the big data database of teaching environment is mainly carried out from the aspects of teaching plan, teaching operation, teaching quality control, basic teaching construction, teaching management and organization, teaching research and so on. The decision-making personnel of applicationoriented undergraduate colleges should unify their thinking and understanding, strengthen their leadership, formulate corresponding systems for the construction of big data database of teaching environment, and make the teaching environment more standardized so as to facilitate the smooth development of the construction of the big data database of teaching environment.

\subsection{Infiltration of big data into teachers' teaching methods}

The use of big data in students' learning feedback, improving learning methods and customizing personalized learning may be the work most colleges are willing and able to carry out at present, or the fastest response that colleges can make to the advent of the big data era. Teachers should actively respond to the challenge of big data and change teaching methods. When students study on the Internet, the function of teachers will change. Teachers can no longer teach according to the original teaching method. They must obtain learning information from education data, understand students' learning behavior and learning effect, and conduct individual guidance.

New learning methods, such as ubiquitous learning, classroom turnover, online and offline mixed teaching, have been widely implemented in colleges. Various massive open online course platforms offer a large number of high-quality courses. Colleges should actively build online learning platforms to support new learning modes. The network platform should not only have rich teaching resources, but also be able to carry out teaching, student status management, learning process records, etc. On such platform, students can select courses, study, test, self-test and communicate with teachers and classmates. Teachers can use the network to prepare lessons, interact with teachers and students, and guide students to study. Finally, the online learning platform is used to collect and analyze the students' daily learning situation, optimize the teaching mode, realize personalized learning that meets the students' individual needs, and optimize the learning content, learning time and learning methods through probability prediction.

\subsection{Secure big data application mode}

How to ensure the security and privacy of data in the process of collection, transmission or sharing is an important issue in the big data era. However, if we stop because we are afraid of the risks brought by big data, our education will also be restricted by the past, so we should not focus on the risks in the face of big data, but should focus on the use and management of data. Of course, as college administrators, the first thing to do is to use data to manage with the permission of laws and policies. In addition, skilled experts are required to assess the risk of data use, control its complexity, set the type and time of data storage, reduce the harm of data through multiple security measures, and ensure that the data brings us efficient, precise and scientific education management. 
There is no doubt that big data will help and lead us into intelligent learning and intelligent management. How to understand the essence of big data, how to cultivate the big data thinking of managers and users, how to mine and embody the value of big data are all problems we face and need to study. Colleges must speed up the practice and research of big data management and use big data to reallocate education resources to provide a better experience for various purpose ranging from public service to students' personalized development.

\section{Conclusions}

In conclusion, the application-oriented colleges and universities refer to the undergraduate colleges with application-oriented orientation rather than scientific research-oriented orientation. Application-oriented undergraduate education has played a positive role in meeting the needs of China's economic and social development, in meeting the needs for high-level application-oriented talents and in promoting the popularization of higher education in China. Colleges have common features in the aspects of management mode in the big data era and the composition of big data database, but each has its own emphasis on the key points, collection points and tracking points of data, which indicates that there are differences between application-oriented colleges and research-oriented colleges in the construction of soft environment big data database.

Under the background of big data era, application-oriented undergraduate management should keep pace with the times, strengthen the application of big data technology, comprehensively collect all kinds of information and data by scientific and technological means, provide guarantee for the formulation of scientific teaching manage ment, learning management and scientific research management strategies, and lay a good foundation for the innovation of colleges management mode based on the comprehensive application of funds, facilities and other resources of colleges. It is worth noting that in the application of advanced technologies such as big data, attention should be paid to the protection of data information to avoid the leakage of teachers' and students' privacy and personnel information.

\section{Acknowledgments}

This work was supported by National Education Innovation Science Research Planning Project (CMAS180305)

\section{References}

[1] S. Tan, "Stick on student-oriented, form the humanistic idea of higher education administration: view china's higher education administration from America's higher education development," Journal of Chengdu University of Technology (Social Sciences), no.4, pp.71-73, (2017)

[2] V. Mayer-Schonberger and K. Cukier, "Big data: A revolution that will transform how we live, work, and think," Zhejiang People's Publishing House, (2013)

[3] S. Chen, L. Meng, and H. Zhang, "Education policy evidence in the big data era: the uses of evidence-based policy for modern education governance and scientific educational policy-making in China," Global Education, no.2, pp.4-39, (2014)

[4] Y. Zhang and Z. Zhao, "Reflections on inspiration for education from thinking mode in big data age," Research in Educational Development, no.21, pp.45-49, (2013)

[5] X. Tao, X. Hu, Y. Liu, "Overview of big data research,” Journal of System Simulation, no. 8, pp.12-15, (2013) 
Innovation of Education Management of Application-Oriented Undergraduate Colleges in Big Data Era

[6] B. Hu and Z. Wang, "The role and challenge of "big data' to education and the trend of educational change," Modern University Education, no.4, pp.99-101, (2015)

[7] M. Chang, "Research on university management mode in big data era," Electronics World, no.1, pp.67-70 (2016) 